\title{
MECHANISM OF HYDROGEN FORMATION IN SOLAR PARABOLIC TROUGH RECEIVERS ${ }^{*}$
}

\author{
Luc Moens \\ Daniel M. Blake \\ National Renewable Energy Laboratory. Senior Scientist - Ph.D. \\ National Renewable Energy Laboratory. Principal Scientist - Ph.D. \\ National Renewable Energy Laboratory, 1617 Cole Boulevard, Golden, Colorado 80401, USA. \\ 303-384-6265; luc_moens@nrel.gov
}

\begin{abstract}
Solar parabolic trough systems for electricity production are receiving renewed attention, and new solar plants are under construction to help meet the growing demands of the power market in the Western United States. The growing solar trough industry will rely on operating experience it has gained over the last two decades. Recently, researchers found that trough plants that use organic heat transfer fluids (HTF) such as Therminol VP-1 are experiencing significant heat losses in the receiver tubes. The cause has been traced back to the accumulation of excess hydrogen gas in the vacuum annulus that surrounds the steel receiver tube, thus compromising the thermal insulation of the receiver. The hydrogen gas is formed during the thermal decomposition of the organic HTF that circulates inside the receiver loop, and the installation of hydrogen getters inside the annulus has proven to be insufficient for controlling the hydrogen build-up over the lifetime of the receivers. This paper will provide an overview of the chemical literature dealing with the thermal decomposition of diphenyl oxide and biphenyl, the two constituents of Therminol VP-1.
\end{abstract}

Keywords: parabolic trough receivers; hydrogen; heat transfer fluid; diphenyl oxide; biphenyl

\section{Introduction}

Solar parabolic trough systems for electric power production have been operating in the Western United States for over two decades, and new trough plants are currently under construction to help meet the growing demands of the power market. ${ }^{i}$ These solar plants consist of large fields of modular parabolic trough collectors that capture and focus the sensible solar heat radiation onto a linear receiver tube that is placed in the focal line of the parabolic trough collectors. A heat transfer fluid (HTF) circulates through the receiver tube, and transports the thermal energy to a heat exchanger system in a power block where high-pressure superheated steam is generated. This steam is then used to drive a steam turbine/generator to produce electricity. The receiver tube loop that runs through the solar field is made up of a modular series of heat collection elements (HCE). Each HCE is composed of a steel tube that contains the HTF, and an outer glass tube that maintains a vacuum around the hot steel tube. This vacuum annulus serves as a thermal insulator while allowing for maximum absorption of the solar thermal radiation by each HCE.

Researchers have tested several types of heat transfer fluids in solar fields, e.g., mineral oils, silicones, heavy aromatic oils, and molten salts. Among these, the most cost-effective and most practical organic oil is that composed of a eutectic mixture of diphenyl oxide (DPO, or (di)phenyl ether) and biphenyl, which is better known under the trademark names of Therminol VP-1 or Dowtherm A. ${ }^{1 \text {,ii }}$ The eutectic formulation is composed of $73.5 \%$ DPO and $26.5 \%$ biphenyl, and has a pour point of $12^{\circ} \mathrm{C}$ (Fig. 1).

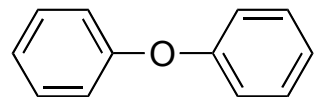

diphenyl oxide

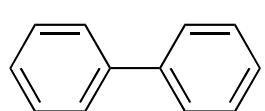

biphenyl

Figure 1. Components of Therminol VP-1 and Dowtherm A

\footnotetext{
* This work has been authored by an employee of the Midwest Research Institute under Contract No. DE-AC36-99GO10337 with the U.S. Department of Energy. The United States Government retains and the publisher, by accepting the article for publication, acknowledges that the United States Government retains a non-exclusive, paid-up, irrevocable, worldwide license to publish or reproduce the published form of this work, or allow others to do so, for United States Government purposes.
} 
In spite of the relatively low boiling point of this oil $\left(257^{\circ} \mathrm{C}\right)$ it has been used successfully in commercial solar trough plants at operating temperatures as high as $400^{\circ} \mathrm{C}$ for many years. Yet, even though this has led to very reliable and continuous power production for two decades, recent observations in several solar fields have revealed significant heat losses in a large number of HCE modules. These thermal losses have been attributed to the slow permeation of traces of hydrogen gas through the steel tube wall into the vacuum annulus of several HCE modules thereby compromising the thermal insulation capacity of the annulus.

Since the construction of the first solar trough systems two decades ago, it has been common practice among manufacturers of receiver tubes to incorporate so-called "hydrogen getters" inside the vacuum space of each HCE. These absorb any traces of hydrogen gas that might be formed over time as a result of thermal degradation of the HTF. Recent observations, however, indicate that the long-term exposure of the organic $\mathrm{HTF}$ to $400^{\circ} \mathrm{C}$ temperatures can lead to hydrogen pressures that exceed the gas-absorbing capacity of the hydrogen getters, thereby causing the significant heat losses that are currently observed in several solar trough plants.

This problem is gaining considerable importance as the trough industry is examining new technologies to drive the cost of electricity down. These include thermal energy storage to increase the efficiency of current as well as future plant designs. In an effort to better understand the causes of the hydrogen gas formation and also to develop possible strategies for mitigating the gas build-up, this paper presents a review of the most relevant chemical and patent literature relating to the thermal decomposition of biphenyl and diphenyl oxide. Our intention is to gather literature data that support the notion that the hydrogen formation proceeds at temperatures around $400^{\circ} \mathrm{C}$ as a result of thermal degradation of the organic HTF.

\section{$2 \quad$ Literature Review}

\subsection{Thermal decomposition of biphenyl and DPO}

Since the 1930s researchers have known that the thermal decomposition of biphenyl and DPO above $400^{\circ} \mathrm{C}$, results in the formation of tar-like materials with very high melting points $\left(c a .200^{\circ} \mathrm{C}\right)$ that were then touted as thermally stable heat transfer fluids. ${ }^{\text {iii, iv }}$ At that time, the composition of the thermal product mixture could not be determined due to the lack of appropriate analytical tools.

During the early 1960 s, more details became available regarding the thermal decomposition of pure biphenyl at $425^{\circ} \mathrm{C}$ as this compound was regarded as a potentially useful coolant for nuclear reactors. This temperature was found to be sufficient to cause pyrolytic decomposition with formation of a gaseous mixture that contained hydrogen in addition to carbon monoxide and $\mathrm{C}_{1}-\mathrm{C}_{3}$ hydrocarbons. ${ }^{\mathrm{v}, \mathrm{vi}}$ The reaction mixture also contained aromatic hydrocarbons such as benzene, terphenyl, and quaterphenyls. The formation of these polyphenyls clearly indicated that polymerization of the phenyl groups plays a significant role in the pyrolysis of biphenyl. Shortly thereafter, two significant studies were published wherein Dowtherm $A$ was investigated as a working fluid for potential use in Rankine cycle power systems. ${ }^{\text {vii, viii }}$ This work showed that circulating this fluid in a test loop kept at $700^{\circ} \mathrm{F}\left(371^{\circ} \mathrm{C}\right)$ for 10,000 hours, resulted in the measurable build-up of gaseous products above the fluid, which again included hydrogen. In addition, aromatic degradation products such as benzene, phenol and terphenyls were identified among the reaction products. Considering that the Dowtherm A sold today is rated for operating temperatures as high as $400^{\circ} \mathrm{C}$, it appears that other factors may have caused the degradation. As we will discuss later, the presence of impurities in the fluid may have been the culprit.

Because of the challenges associated with measuring thermal decomposition rates at $400-450^{\circ} \mathrm{C}$, Proksch et al. conducted a systematic kinetic study of the thermal decomposition of pure biphenyl under strict control of the reaction conditions. ${ }^{\text {ix }}$ They found that the careful exclusion of oxygen from the pyrolysis reactor and following the kinetics for thermal decomposition of $\leq 1 \%$ of the biphenyl sample were the keys to obtaining consistent results. Because the thermal decomposition of biphenyl at $400^{\circ} \mathrm{C}$ was considered too slow for a practical kinetic study in the laboratory, the thermal decomposition study was carried out at temperature increments between $420^{\circ} \mathrm{C}$ and $465^{\circ} \mathrm{C}$. At $\leq 1 \%$ conversion of the biphenyl the formation of secondary reaction products was avoided and a rate expression for the initial thermal degradation could be derived as a function of temperature using a first-order kinetics approach (Eq. 1):

$$
\log \mathrm{V}=20.59-(15,770 / \mathrm{T}) \quad \text { (Eq. 1) }
$$


where $\mathrm{V}$ is the rate of the pyrolysis in $\% / \mathrm{h}$ for low conversions of liquid biphenyl, and $\mathrm{T}$ is the temperature $(\mathrm{K})$. Assuming first-order kinetics, this rate expression can be transformed into Equation 2:

$$
\log \mathrm{k}=15.03-(15,770 / \mathrm{T})
$$

wherein $\mathrm{k}$ is the first-order rate of the pyrolysis in $\mathrm{s}^{-1}$. Using this approach, an Arrhenius activation energy of $302 \mathrm{~kJ} / \mathrm{mol}(72.1 \mathrm{kcal} / \mathrm{mol})$ was derived. Analysis of the pyrolysis mixture revealed the formation of hydrogen gas, and a mixture of benzene, terphenyl, and quaterphenyl isomers. Interestingly, the concentration of benzene in the aromatic fraction increased from less than $5 \%$ at $420^{\circ} \mathrm{C}$ for $150 \mathrm{~h}$, to $23 \%$ at $465^{\circ} \mathrm{C}$ in $6 \mathrm{~h}$, thereby clearly demonstrating the rapid breakdown of biphenyl within a relatively small temperature range above $420^{\circ} \mathrm{C}$.

The cleavage of the strong carbon-carbon single bond in biphenyl was also of great interest to the fossil fuel industry since this aromatic structure is common to some of the most thermally stable compounds in coal and petroleum-derived aromatic streams. Extensive studies during the 1990s demonstrated that heating a mixture of biphenyl and alkanes at $450^{\circ} \mathrm{C}$ resulted in the rapid thermal decomposition of the aromatic compound. ${ }^{\mathrm{x}}$ The key step in this process is the breakdown of the alkane which releases highly reactive hydrogen atoms that attack the biphenyl as shown in Figure 2. The $\mathrm{C}-\mathrm{C}$ bond cleavage generates a phenyl radical that can engage in a chain reaction.

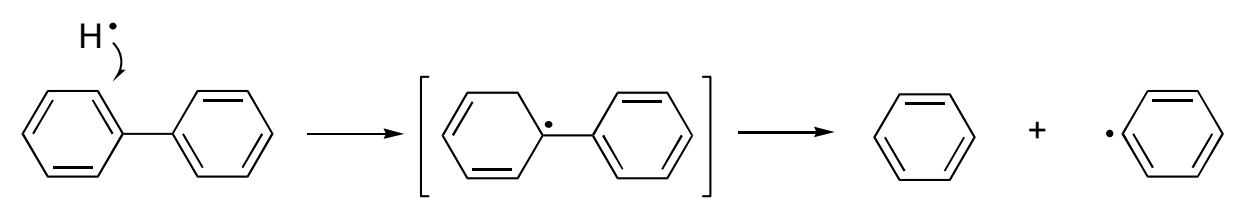

Figure 2. Cleavage of biphenyl by hydrogen atom

Likewise, the direct thermal cleavage of biphenyl also forms phenyl radicals, and these two steps combined can then initiate a chain reaction. This leads to the production of benzene, polyphenyl compounds (e.g. terphenyl), and also more hydrogen atoms that ultimately recombine to form hydrogen gas (Fig. 3). ${ }^{10}$

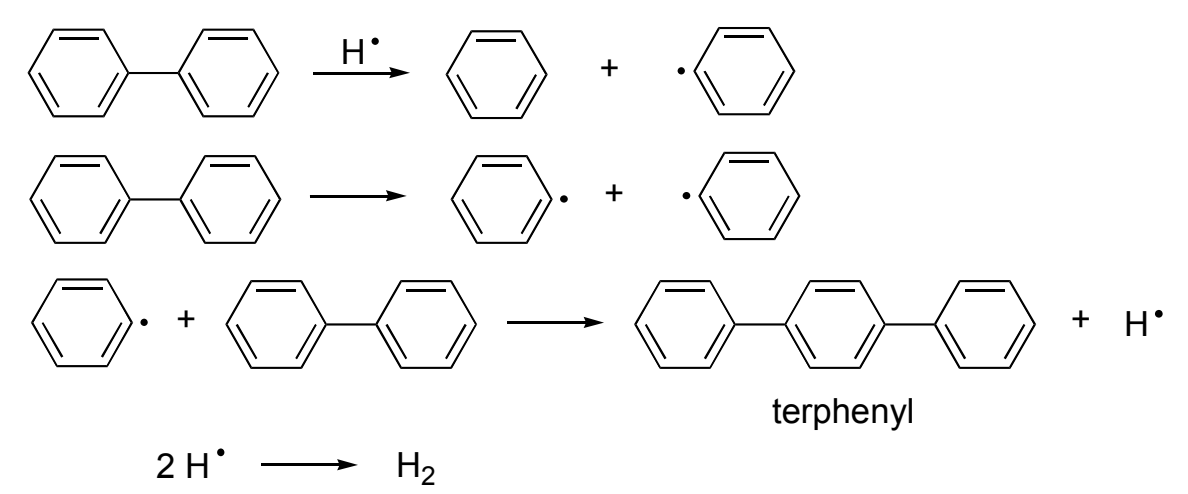

Figure 3. Radical-induced formation of polyphenyls and hydrogen

In other words, the rate of the thermal decomposition of biphenyl may be influenced by the presence of dissolved organic impurities, as these can act as a source of hydrogen atoms.

DPO has been investigated as part of coal liquefaction research, and bond dissociation energies for the C-O bond have been reported that range from 76 to $80 \mathrm{kcal} / \mathrm{mol}^{\text {xi, xii }}$ As shown in Figure 4, the homolytic dissociation of DPO results in the formation of phenoxy and phenyl radicals, while hydrogen atoms can cause cleavage to form benzene and a phenoxy radical in analogy with biphenyl cleavage. 


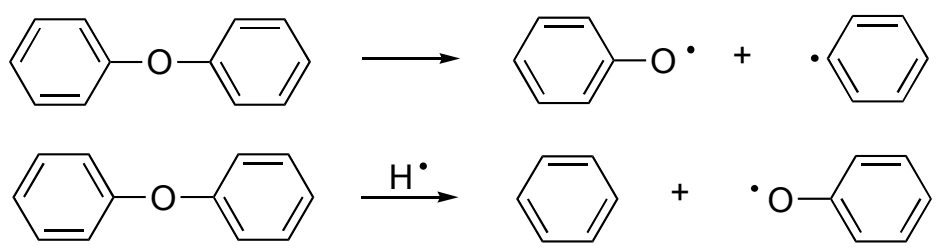

Figure 4. Cleavage reactions of DPO

\subsection{Thermal decomposition of DPO/biphenyl mixtures}

Considering the multitude of reactions that the radical species can engage in, the product slate generated from a mixture of DPO and biphenyl can be expected to be even more complex. We found only one report that describes a study of the thermal degradation of Dowtherm $A$ in a temperature range of $400-425^{\circ} \mathrm{C}$, and that provides some insight into the overall kinetics as well as the products formed during the fluid breakdown. ${ }^{\text {xii }}$ It was found that under static conditions the fluid viscosity increased by $17 \%$ at $425^{\circ} \mathrm{C}$ after $120 \mathrm{~h}$, and this empirical approach suggested that the thermal breakdown of this aromatic mixture involved a polymerization process. The presence of heavier degradation products was confirmed through the use of gel permeation chromatography (GPC). Moreover, a linear correlation was found between the quantitative GPC analysis of these heavy products and the viscosity of the fluid after heating at $400^{\circ} \mathrm{C}, 412.5^{\circ} \mathrm{C}$, and $425^{\circ} \mathrm{C}$, respectively. Using a first-order kinetic approach, an activation energy of $72 \mathrm{kcal} / \mathrm{mol}$ was calculated that fit well with the thermochemical data mentioned earlier for biphenyl. When Dowtherm $A$ was heated at $425^{\circ} \mathrm{C}$ for $120 \mathrm{~h}$, about $8 \%$ of the fluid had degraded to form a mixture of a) gaseous products consisting of hydrogen gas (44\% of the total gas volume) and small hydrocarbons, and b) a fraction containing the aromatic compounds shown in Figure 5.

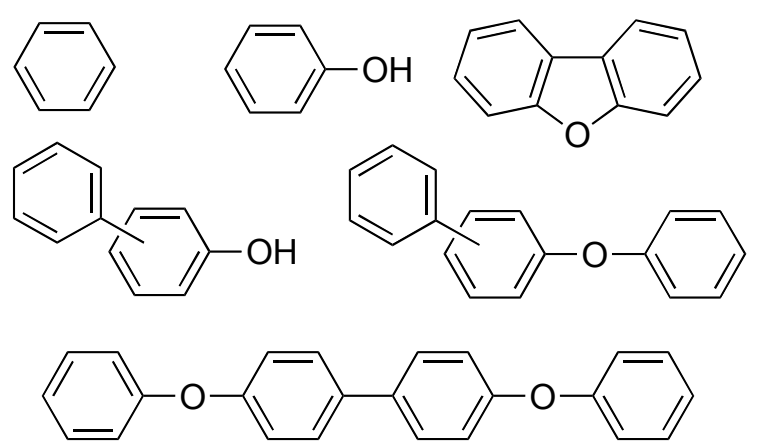

Figure 5. Aromatic compounds formed during thermal breakdown of Dowtherm A

Much heavier aromatics were detected during the GPC analysis, but their structures were not determined. Nevertheless, this work led to the formulation of a plausible mechanistic scheme that explains the formation of hydrogen gas as a significant by-product, as well as the observed aromatic products (Fig. 6). 


\section{Initiation}

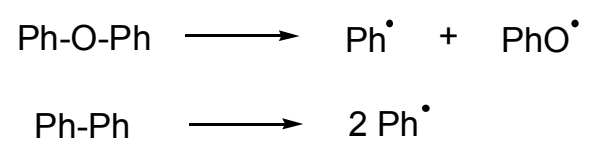

\section{Propagation}

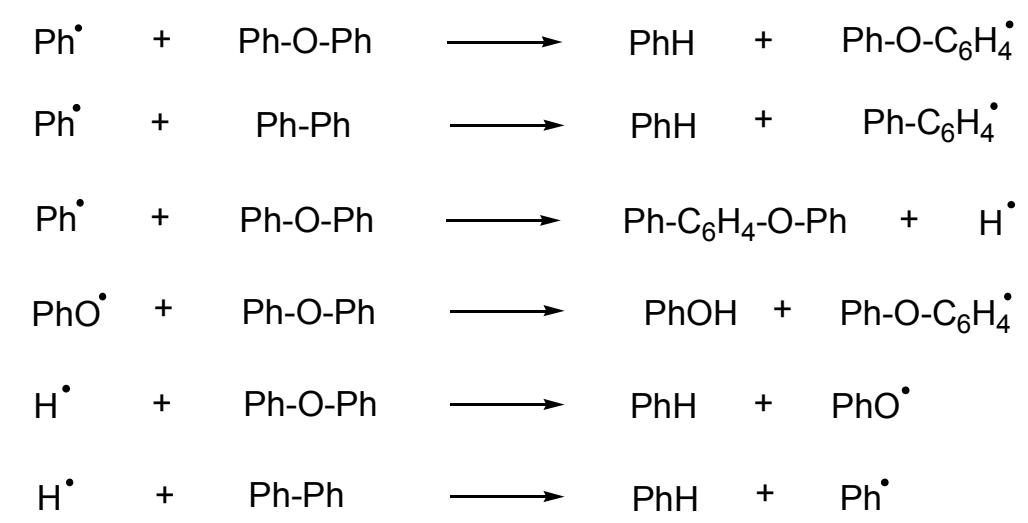

\section{Termination}

$$
\begin{aligned}
2 \mathrm{Ph}-\mathrm{O}-\mathrm{C}_{6} \mathrm{H}_{4}^{\cdot} & \longrightarrow \\
2 \mathrm{C}_{6} \mathrm{H}_{5}^{\cdot} & \longrightarrow \mathrm{Ph}-\mathrm{O}-\mathrm{C}_{6} \mathrm{H}_{4}-\mathrm{C}_{6} \mathrm{H}_{4}-\mathrm{O}-\mathrm{Ph} \\
\mathrm{Ph}^{\cdot}+\mathrm{H}^{\cdot} & \longrightarrow \mathrm{Ph}-\mathrm{Ph} \\
2 \mathrm{H}^{\cdot} & \longrightarrow
\end{aligned}
$$

Figure 6. Proposed mechanism for thermal breakdown of DPO/biphenyl mixtures

$$
\left(\mathrm{Ph}-\mathrm{O}-\mathrm{Ph}=\mathrm{DPO} ; \mathrm{Ph}-\mathrm{Ph}=\text { biphenyl; } \mathrm{Ph}^{\circ}=\mathrm{C}_{6} \mathrm{H}_{5}{ }^{\circ}=\text { phenyl radical }\right)
$$

This "aging" study also demonstrated that the viscosity already changes somewhat around $400^{\circ} \mathrm{C}$, yet the thermal degradation rates are too slow to be measured directly under laboratory conditions. This would explain why this HTF can be used at this temperature in solar trough systems for many years without significant degradation in performance. However, over long periods of time, the hydrogen gas formed during the slow decomposition will accumulate steadily in the HCE to levels that ultimately exceed the capacity of the hydrogen getters. Further evidence comes from "aged" oil taken directly from the receivers in several solar fields. Analysis using gas chromatography revealed the presence of so-called "high boilers" (i.e., heavy aromatics), and these observations are in congruence with the mechanistic hypothesis.

\subsection{Other possible sources of hydrogen in solar receivers}

So far we have focused on reports that deal with the thermal decomposition of nominally pure DPO/biphenyl mixtures, but the observation that hydrogen atoms generated from other non-aromatic molecules can catalyze the decomposition process raises the question of whether impurities in the commercial oils could also act as a source 
of hydrogen atoms, thereby accelerating the thermal breakdown of the fluid at $400^{\circ} \mathrm{C}$. This question was addressed in a study on minimizing the hydrogen permeation rates through the stainless steel wall of a test loop wherein various aromatic heat transfer fluids were circulated at temperatures up to $400^{\circ} \mathrm{C}$ xiv $^{\text {The tests revealed }}$ that the permeation into the vacuum space increased when impurities were present. These impurities included alkyl-substituted aromatics that are strong hydrogen producers at this temperature. The build up of hydrogen in the vacuum space diminished significantly when the impurities were selectively removed from the aromatic fluid. The study did not address to what extent any incipient hydrogen atoms originating from the thermal decomposition of the impurities might participate in the chain reaction shown in Fig. 4. Nevertheless, while removing impurities from the HTF appears to be a good method to increase the lifetime of the $\mathrm{HTF}$ at $400^{\circ} \mathrm{C}$, there will always be some hydrogen formation at these operating temperatures, even with HTF of the highest purity.

Another chemical reaction of diphenyl oxide that should also be discussed here is its direct thermal conversion into dibenzofuran upon contact with the surface of a solid metal oxide catalyst at temperatures in the range of $300-700^{\circ}$ C. $^{\mathrm{xv}, \mathrm{xvi}}$ This process is accompanied by the formation of a stoichiometric amount of hydrogen.

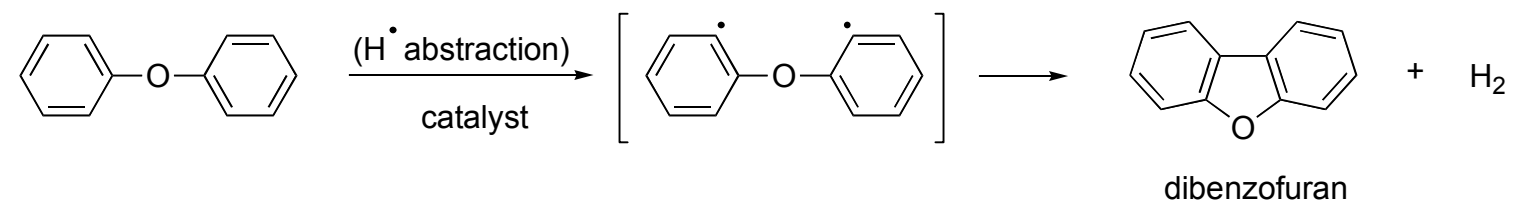

Figure 7. Catalytic conversion of DPO into dibenzofuran

This process presumably involves a radical-type reaction wherein a hydrogen atom is abstracted from one orthoposition in each phenyl ring, followed by ring closure (Fig. 7). This is known to occur with different catalysts, but to the best of our knowledge, the heterogeneous catalysis process has never been described in peer-reviewed literature. More insight in this chemical process is needed, in particular whether metal oxides present at the surface of stainless steel walls would have a catalytic effect. The patent mentions a wide range of catalytically active oxides such as those of magnesium, calcium, aluminum, potassium, titanium, zirconium and lanthanides. Therefore, it would be reasonable to expect the oxides that reside at the surface of the stainless steel could have catalytic activity also. If that is the case, the inside wall in the receiver tube may catalyze the slow thermal conversion of DPO to dibenzofuran and hydrogen gas. Note that dibenzofuran was one of the thermal products in the viscosity test of Dowtherm A, but the influence of the wall material of the test reactor must be further investigated. It is also worth mentioning that, according to a different patent, there is evidence that small concentrations of dibenzofuran in a DPO/biphenyl type HTF are not detrimental to the performance of the fluid, and may even cause a slight depression of the pour point. ${ }^{\text {xvii }}$

\subsection{Alternative organic HTF}

The discussion of organic heat transfer fluids would be incomplete without mentioning other technology areas where such fluids have been investigated. The first is that of nuclear reactor technology that, before the advent of efficient water-cooled systems, had a strong R\&D focus on hydrocarbon-based coolants. This work spanned a period of about four decades starting in the mid 1950s, and several reports have appeared that provide considerable detail on the various organic coolants that were tested. ${ }^{\text {xviii, } x \mathrm{x}, \mathrm{xx}, \mathrm{xxi}}$ The organics comprised mostly commercial formulations based on terphenyl-derived aromatics that had high boiling points $\left(300-400^{\circ} \mathrm{C}\right)$.

Because these formulations also had high melting points, preference was given to a class of materials known by the generic name of Santowax fluids that have a waxy consistency around ambient temperature, and consist of partially hydrogenated terphenyls. Monsanto Co. originally commercialized these formulations under code names such as OS-84 or HB-40, and these fluids were tested in nuclear reactor cores at $400^{\circ} \mathrm{C}$ over time periods spanning many years. One of the drawbacks of these fluids was that they decomposed into a complex mixture of gasses (hydrogen and lower hydrocarbon gases) and liquid products (polycyclic aromatics), and replenishment of the coolant was needed on a continuous basis. Obviously, such fluids would not be suitable for use in solar trough systems, even if the boiling and melting points are much better than those of DPO/biphenyl formulations. 
The development of jet engines and nuclear-powered vehicles also stimulated an intense search for special hightemperature fluids, particularly formulations that could act as lubricants with good flow properties under extreme heat and cold conditions ${ }^{\text {xxii }}$ as well as intense radiation. ${ }^{\text {xxii }}$ This has led to the development of a wide variety of polyphenyl ethers with high boiling points $\left(300-400^{\circ} \mathrm{C}\right)$ and grease-like properties at low temperatures. Unfortunately, their thermal stability is not significantly better than that of the current DPO/biphenyl fluids. ${ }^{\text {xxiv }}$ The structural similarity that exists between these aromatic compounds suggests that the thermal decomposition mechanisms are similar, and thus also their propensity towards hydrogen formation. Because of their application as high-temperature lubricants, the oxidative degradation mechanisms of these heavy aromatics have received most of the attention. ${ }^{\mathrm{xxv}, \mathrm{xxvi}, \mathrm{xxvii}}$

\section{Conclusions}

Perusal of the chemical and patent literature related to the thermal decomposition of biphenyl and diphenyl oxide has provided us with sufficient data to derive a mechanistic model to rationalize the hydrogen gas formation in solar parabolic trough receivers. A number of independent studies were discussed that clearly suggest that thermal fluids such as Therminol $V P-1$ undergo a gradual thermal breakdown when exposed to operating temperatures around $400^{\circ} \mathrm{C}$. The reported kinetic studies have also shown that the degradation process proceeds at a very low rate at $400^{\circ} \mathrm{C}$, but accelerates considerably between $400^{\circ} \mathrm{C}$ and $425^{\circ} \mathrm{C}$. This very slow formation of hydrogen gas inside the steel receiver tube and its permeation into the vacuum annulus over a very long time period causes the observed heat losses in several solar trough fields.

There is ample evidence that the mechanism of the process involves a radical reaction wherein hydrogen gas is formed as a by-product, as well as aromatic oligomers with higher molecular weights (high boilers). In addition, there is strong proof that organic impurities in the fluid can catalyze the thermal breakdown of the HTF through the thermal formation of highly reactive hydrogen atoms (radicals). In other words, the HTF should be of the purest grade from the onset, and must be kept free of organic impurities. Another factor that could contribute to hydrogen formation is the presence of oxide layers at the surface of the steel receiver walls that may have sufficient catalytic activity to convert DPO into dibenzofuran. Unfortunately, further in-depth studies are needed to prove whether this reaction takes place at all inside solar receivers. It appears that the fundamental chemistry behind this catalytic reaction has never been thoroughly investigated.

The inherent thermal instability of the chemical bonds in the DPO/biphenyl fluid precludes any chemical strategies to mitigate the formation of hydrogen gas. The literature on high-temperature coolants and lubricants clearly demonstrates that even the most robust of all organic compounds cannot remain totally intact around $400^{\circ} \mathrm{C}$. Therefore, by far the simplest and probably also most cost-effective approach to avoiding the accumulation of hydrogen in the solar receiver modules would be to vent the fluid system on a regular basis so that the gas does not migrate through the steel receiver wall in the first place.

\section{Acknowledgements}

The authors wish to thank the U.S. Department of Energy for the continued support of the Concentrating Solar Power Program.

\section{References and Notes}

1) Price, H., Lüpfert, E., Kearney, D., Zarza, E., Cohen, G., Gee, R., and Mahoney, R., 2002, “Advances in Parabolic Trough Solar Power Technology,” J. Sol. Energy Eng., 124, p. 109.

2) Moens, L., Blake, D. M., Rudnicki, D. L., and Hale, M. J., 2003, “Advanced Thermal Storage Fluids for Parabolic Trough Systems,” J. Sol. Energy Eng., 125, p. 112.

3) Grebe, J. J. and Stoesser, S. M., 1933, "Synthetic Lubricant and Method of Making Same," U.S. Patent No. $1,905,850$.

4) Grebe, J. J., and Stoesser, S. M., 1936, "Heat Storage and Transfer Agent,” U.S. Patent No. 2,033,702.

5) Rainey, W. T., Jr. and Yeatts, L. B., Jr., 1963, "Studies on Pyrolysis Products of Pure Biphenyl," USAEC Report TID-7641, p. 189.

6) Rainey, W. T., Jr., Attrill, J. E., and Yeatts, L. B., Jr., 1963, “Gas Chromatographic Analysis of Biphenyl Pyrolytic Products," Report ORNL-TM-523. 
7) Adam, A. W., Niggemann, R. E., and Sibert, L. W., 1968, "Thermal Stability Determination of Biphenyl and the Eutectic of Biphenyl and Phenyl Ether in a Rankine Cycle System," Intersoc. Energy Convers. Eng. Conf. Rec., 1, pp. 398-406.

8) Leighton, G. S., 1968, “The Organic Rankine Cycle,” Intersoc. Energy Convers. Eng. Conf. Rec., 1, pp. 389-97.

9) Proksch, E., Strigl, A., Wagner-Löffler, M., and Szinovatz W., 1985, "Zur thermischen Stabilität von Diphenyl," Chem.-Ing.-Tech., 2, pp 148-151.

10) Cook, B. R., Wilkinson, B. B., Culross, C. C., Holmes, S. M., and Martinez, L. E., 1997, "Hydrogen Transfer Induced Cleavage of Biaryl Bonds", Energy \& Fuels, 11, pp. 61-75.

11) van Scheppingen, W., Dorrestijn, E., Arends, I., and Mulder, P., 1997, "Carbon- Oxygen Bond Strength in Diphenyl Ether and Phenyl Vinyl Ether: An Experimental and Computational Study,” J. Phys. Chem. A, 101, pp. 5404-5411.

12) Poutsma, M. L., 1990, "Free-Radical Thermolysis and Hydrogenolysis of Model Hydrocarbons Relevant to Processing of Coal," Energy \& Fuels, 4, pp. 113-131.

13) Arnold, C., Jr., 1978, "Evaluation of Organic Coolants for the Transportation of LMFBR Spent Fuel Rods", Report SAND77-1486.

14) Gambell, J. W., Herber, J. F., and Thompson, Q. E., 1991, "Heat Transfer Fluids,” U.S. Patent No. $5,075,022$.

15) Fishel, N. A., 1977, "Conversion of Diphenylethers to Dibenzofurans using Catalysts containing Ceria," U.S. Patent No. 4,009,185.

16) Walsh, W. D., and Gunn, R. W., 1963, "Preparation of Dibenzofuran", U.S. Patent No. 3,108,121.

17) Okazaki, H., Inoue, M., and Ishida, H., 1994, "Heat-Transfer Medium Compositions," U.S. Patent No. $5,281,349$.

18) Gierszewski, P., and Hollies, R. E., 1987, “Organic Coolants and Their Applications to Fusion Reactors," Nuclear Eng. Design/Fusion, 4, pp. 223-236.

19) Gierszewski, P., and Hollies, R. E., 1986, "Organic Coolants and Their Applications to Fusion Reactors," Canadian Fusion Fuels Technology Project, Report AECL-8405.

20) Smee, J. L., Puttagunta, V. R., Robertson, R. F. S., and Hatcher, S. R., 1975, “Organic Coolant Summary Report,” Report AECL-4922.

21) Natalizio, A., Hollies, R. E., and Gierszewski, P., 1993, "Safety and Enviromental Aspects of Organic Coolants for Fusion Facilities," J. Fusion Energy, 12, pp. 177- 181.

22) Mahoney, C. L., Barnum, E. R., Kerlin, W. W., Sax, K. J. and Saari, W. S., 1960, "Polyphenyl Ethers as High-Temperature Radiation-Resistant Lubricants," J. Chem. Eng. Data, 5, pp.172-180.

23) Mahoney, C. L., Barnum, E. R., Saari, W. S., Sax, K. J., and Kerlin, W. W., 1959, "Nuclear Radiation Resistant High Temperature Lubricants", WADC Technical Report 59-173.

24) Blake, E. S., Hammann, W. C., Edwards, J. W., Reichard, T. E., and Ort, M. R., 1961, "Thermal Stability as a Function of Chemical Structure," J. Chem. Eng. Data, 6, pp. 87-98.

25) Ravner, H. Moniz, W. B., and Blachly, C. H., 1972, "High-Temperature Stabilization of Polyphenyl Ethers by Inorganic Salts," ASLE Transactions, 15, pp. 45-53.

26) Archer, W. L., and Bozer, K. B., 1966, “Oxidative Degradation of the Polyphenyl Ethers,” Ind. Eng. Chem. Prod. Res. Dev., 5, pp. 145-9.

27) Ravner, H., Russ, E. R., and Timmons, C. O., 1963, "Antioxidant Action of Metals and Metal-Organic Salts in Fluoroesters and Polyphenyl Ethers,” J. Chem. Eng. Data, 8, pp. 591-6. 